\title{
What Factors Influence the Choice of Anesthesiology in a Moroccan Medical School?
}

\author{
Abdelhamid Hachimi ${ }^{*}{ }^{(1)}$, Soulaymane Rachda ${ }^{1}$, Mohamed El-Alaoui ${ }^{1}$, \\ Leonard Biantona Bouebazebi ${ }^{1}$, Rajaa Belmaati ${ }^{1}$, Meriem Essafti ${ }^{1}$, \\ Fatima-Ezzahra Saroukh'1, Mohamed Amine ${ }^{2}$
}

${ }^{1}$ Medical Intensive Care Unit, Faculty of Medicine and Pharmacy, Cadi Ayyad University, Marrakech, Morocco ${ }^{2}$ Community Medicine and Public Health Department, Research Laboratory, Biosciences and Health, Faculty of Medicine and Pharmacy, Cadi Ayyad University, Marrakech, Morocco

Email: *abdelhachimi@gmail.com

How to cite this paper: Hachimi, A., Rachda, S., El-Alaoui, M., Bouebazebi, L.B., Belmaati, R., Essafti, M., Saroukh, F.-E. and Amine, M. (2022) What Factors Influence the Choice of Anesthesiology in a Moroccan Medical School? International Journal of Clinical Medicine, 13, 57-65. https://doi.org/10.4236/ijcm.2022.131005

Received: October 28, 2021

Accepted: January 21, 2022

Published: January 24, 2022

Copyright () 2022 by author(s) and Scientific Research Publishing Inc. This work is licensed under the Creative Commons Attribution International License (CC BY 4.0)

http://creativecommons.org/licenses/by/4.0/

\begin{abstract}
Objective: To determine factors influencing anesthesiology choice among resident doctors at the medical school of Marrakech. Materials and Methods: We have conducted a descriptive cross-sectional study based on an anonymous questionnaire. Results: A total of 406/672 questionnaires were returned, with a female/male sex ratio of 1.07. The duration of the training (OR: 3.3; CI 95\%: $1.74-6.23 ; \mathrm{p}<0.001$ ), intellectual challenge (OR: 3.02; CI 95\%: 1.69 5.37; $\mathrm{p}<0.001$ ), doctor-patient relationship (OR: 2.22; CI 95\%: 1.02 - 4.84; $\mathrm{p}$ : 0.04), and financial aspects (OR: 2.14; CI 95\%: 1.09 - 4.21; p: 0.02) were independent factors that influenced the choice of anesthesiology. Conclusion: we recommend the succeeding: 1) Support students in their choice; 2) Correct misconceptions about certain specialties; 3) Promote clinical clerkship; 4) Encourage mentorship; 5) Increase the salary of at-risk specialties.
\end{abstract}

\section{Keywords}

Anesthesiology, Career Choice, Influencing Factors, Resident Doctor

\section{Introduction}

Any health policy with good performance indicators and responsiveness to critical situations is conditioned by the availability of human resources in sufficient quantity and quality. The Moroccan Ministry of Health has published a health map that gives an overview of the healthcare workers in 2019 for 35,478,393 inhabitants [1]. In the public sector, the number of doctors was 12,034, including 3857 general practitioners, 7559 specialist doctors, 458 dentists, and 160 phar- 
macists. Morocco faces a shortage of medical specialists in the public sector. This sector has counted only 492 pediatricians, 456 gynecologists, 439 anesthesiologists, 402 radiologists, 350 traumatologists, 344 visceral surgeons, 330 ophthalmologists, 309 cardiologists, 255 nephrologists, 222 psychiatrists, 211 dermatologists, and 185 urologists. For some specialties, the situation is alarming, particularly for neurosurgery (134 physicians), oncology (107 physicians), hematology (63 physicians), nuclear medicine (47 physicians), and critical care medicine (42 physicians).

According to social background, many factors affect anesthesiology choice as a career; these factors vary from one country to another. In a sizeable Brazilian cohort among 4601 medical students, Guilloux et al. [2] identified the factors that impacted the decision to pursue anesthesiology as a career: gender male ( $\mathrm{p}$ $=0.000)$, other medical doctors in the family $(\mathrm{p}=0.014)$, prefer to work in the hospital $(\mathrm{p}=0.002)$, prestige $(\mathrm{p}=0.018)$, and the social responsibility $(\mathrm{p}=$ $0.030)$.

It would be interesting to know the criteria determining the career choice to provide well-founded elements for decision-makers to correct the imbalance in the distribution of different specialties. Consequently, we surveyed resident doctors of the Faculty of Medicine and Pharmacy of Marrakech to highlight the factors influencing anesthesiology choice.

\section{Materials and Methods}

\subsection{Setting}

The setting of this study was the Faculty of Medicine and Pharmacy of Marrakech, Morocco. It produces general practitioners and surgical/medical specialists. The medical curriculum includes three cycles; the first lasts two years, the second lasts three years, and the third lasts two years, followed by 2 -year internship and residency programs of varying lengths of time according to specialty. The residency program is also accessible for non-intern students after the three cycles and thesis defense.

\subsection{Study Design}

We performed a cross-sectional observational study on the residents' perceptions to determine factors influencing their choice over four months (June to September 2019). We included all residents of our institution in grades 1 through $4 / 5$ in a self-administered survey. We conceived and adapted the questionnaire based on the Murdoch et al. study [3]. It comprehended two sections; the first contained socio-demographic data and information about specialty and the second contained factors influencing their choice. It was distributed at clinical training wards by a resident doctor. We used a 5-Likert scale ranging from strongly disagree (1) to strongly agree (5).

Reliability coefficients for the questionnaires were determined, resulting in an alpha Cronbach $(\alpha)$ of 0.817 . 


\subsection{Statistical Analysis}

The data were analyzed using the SPSS 10.0 software package (IBM, Armonk, NY). Statistical analysis was descriptive, univariate, and multivariate. Qualitative variables were presented by numbers (n) and percentages (\%), and quantitative variables by means $(\mathrm{m})$ and standard deviations S.D. $( \pm)$. For comparing categorical variables, we used: Fisher Exact test or Chi-square test in univariate analysis and binary logistic regression in multivariate analysis for anesthesiology. A p-value of $<0.05$ was considered significant.

\subsection{Ethical Aspects}

Ethically, participation was voluntary and anonymous, and the confidentiality of the information collected during the study was guaranteed. We afforded information notes to all participants before filling the questionnaire.

\section{Results}

Of the 672 questionnaires distributed, 406 were returned (60.4\%). The mean age was $29 \pm 2.2$ years, and the female/male sex ratio was 1.07 . Table 1 summarizes the remaining socio-demographic characteristics of the 406 resident doctors.

In the univariate analysis, duration of the training $(\mathrm{p}<0.001)$, interest in the practice of procedures $(\mathrm{p}<0.001)$, intellectual challenge $(\mathrm{p}=0.01)$, and financial aspects $(\mathrm{p}=0.03)$ were the influencing factors. In the multivariate analysis, duration of the training, intellectual challenge, doctor-patient relationship, and financial aspects were independent factors that influenced anesthesiology choice. Besides, the participants did not choose it because of the absence of a mentor model, overloading work, and lack of time for family (Table 2).

\section{Discussion}

In Morocco, we have had 1.2 anesthetists/100,000 inhabitants, according to the recent statistics in 2019 [1]. However, the goal of the World Health Organization, the World Federation of Societies of Anesthesiologists, and the Lancet Commission on Global Surgery is at least 20 SAO (surgeon-anesthetist-obstetrician) per 100,000 population by 2030 to ensure safe anesthesia [4] [5] .

Factors affecting the choice of anesthesiology as a career vary from one country to another and according to social background. In our context, these factors were duration of the training (four years for medical specialties compared to surgical ones), intellectual challenge, doctor-patient relationship, and financial aspects. Oku et al. [6], in Nigeria among 105 graduating medical students at the University of Calabar, stated that the predictors for choosing anesthesia were personal interests in $81 \%$, future job opportunities in $63 \%$, the requirement of specialized skill in $62 \%$, and influence by a mentor in 30\%. Among 183 undergraduate final-year students of the University of Ghana School of Medicine and Dentistry, Abdul-Rahman et al. [7] showed that causes for not choosing anesthesia were anesthesia is "boring and not interesting", "complex and difficult to understand", "delicate and risky" and very "demanding". 
Table 1. Socio-demographic characteristics of the 406 participants.

\begin{tabular}{|c|c|c|c|}
\hline \multicolumn{2}{|c|}{ Variables } & $\begin{array}{c}\text { Number } \\
\text { (n) }\end{array}$ & $\begin{array}{c}\text { Percentage } \\
(\%)\end{array}$ \\
\hline \multirow{2}{*}{ Geographic origin } & Rural & 49 & 12 \\
\hline & Urban & 357 & 88 \\
\hline \multirow{2}{*}{ Home medical school } & Marrakech & 366 & 90 \\
\hline & Others & 40 & 10 \\
\hline \multirow{2}{*}{ Marital status } & Single & 274 & 67.5 \\
\hline & Married & 132 & 32.5 \\
\hline \multirow{5}{*}{ Father's education level } & Illiterate & 24 & 6 \\
\hline & Primary & 21 & 5 \\
\hline & Secondary & 24 & 6 \\
\hline & High school & 53 & 13 \\
\hline & University & 284 & 70 \\
\hline \multirow{5}{*}{ Mother's education level } & Illiterate & 61 & 15 \\
\hline & Primary & 42 & 10 \\
\hline & Secondary & 32 & 8 \\
\hline & High school & 49 & 12 \\
\hline & University & 222 & 55 \\
\hline \multirow{2}{*}{ Parents' profession } & Healthcare worker & 69 & 17 \\
\hline & Physician & 35 & $51(35 / 69)$ \\
\hline \multirow{5}{*}{ Year of the residency study } & First & 162 & 40 \\
\hline & Second & 101 & 25 \\
\hline & Third & 61 & 15 \\
\hline & Fourth & 65 & 16 \\
\hline & Fifth & 17 & 4 \\
\hline \multirow{10}{*}{ Specialty } & Obstetric Gynecology & 37 & 9 \\
\hline & Anesthesiology & 32 & 8 \\
\hline & Traumatology & 20 & 5 \\
\hline & Ophthalmology & 20 & 5 \\
\hline & Pediatrics & 20 & 5 \\
\hline & Cardiology & 20 & 5 \\
\hline & Visceral surgery & 20 & 5 \\
\hline & Radiology & 20 & 5 \\
\hline & Biology & 16 & 4 \\
\hline & Endocrinology & 16 & 4 \\
\hline
\end{tabular}




\begin{tabular}{ccc}
\hline Gastrohepatology & 16 & 4 \\
Oncology-Radiotherapy & 16 & 4 \\
Psychiatry & 12 & 3 \\
Urology & 12 & 3 \\
Neurosurgery & 12 & 3 \\
Nephrology & 12 & 3 \\
Dermatology & 12 & 3 \\
Maxillo-facial surgery & 12 & 3 \\
Ear nose and throat & 12 & 3 \\
Neurology & 12 & 3 \\
Pneumology & 12 & 3 \\
Hemato & 9 & 2 \\
Pathology & 9 & 2 \\
Rheumatology & 9 & 2 \\
Internal medicine & 9 & 2 \\
Others & 9 & 2 \\
\hline
\end{tabular}

Table 2. Independent factors for the choice of anesthesiology.

\begin{tabular}{cccc}
\hline Factors & Odds ratio & $95 \% \mathrm{CI}$ & $\mathrm{p}$ \\
\hline Duration of the training & 3.3 & $1.74-6.23$ & $<0.001$ \\
Doctor-patient relationship & 3.02 & $1.69-5.37$ & $<0.001$ \\
Intellectual challenge & 2.22 & $1.02-4.84$ & 0.04 \\
Financial aspects & 2.14 & $1.09-4.21$ & 0.02 \\
Influence of mentor model & 0.20 & $0.07-0.57$ & 0.003 \\
Work overload & 0.25 & $0.12-0.54$ & $<0.001$ \\
Time for the family & 0.22 & $0.10-0.46$ & $<0.001$ \\
\hline
\end{tabular}

In Punjab and among 185 post-graduate students and consultants, Asad et al. [8] indicated that the most frequent factors that influenced the choice were the opportunity to do procedures in $65.9 \%$, promotion prospects in $58.4 \%$, time for family in $58.4 \%$, the chance of an overseas job in $55.7 \%$, the diversity of clinical specter in 54.6\%, and intellectual challenge in 50.8\%. In Saudi Arabia at the King bin Abdulaziz University for Health Sciences and among 236 medical students in the 5th and 6th years, Alkhilaiwi et al. [9] mentioned that lifestyle in 30\%, influence from family/peers in $19 \%$, patient care aspects in $17 \%$, fundamental science/ research aspect in 15\%, and financial aspect in $14 \%$ affected the decision for anesthesiology. In India, among 190 post-graduate anaesthesiology students at 
the UCMS and GTB Hospital-Delhi, Tyagi et al. [10] reported that income in $67.7 \%$, the opportunity to perform procedures in $64.1 \%$, the diversity of clinical specter in $63.8 \%$, the chance of overseas work in $57.2 \%$, time for family in $53.7 \%$, intellectual challenge in $51.6 \%$, and the inaccessibility of other specialties in $50 \%$ were the affecting factors.

In Brazil, Guilloux et al. [2] conducted a national survey among 4601 new medical school graduates in 2015. They noted that the factors that impacted the decision to pursue anesthesiology as a career were gender male (RR: 1.394; 95\% CI: $1.234-1.574 ; \mathrm{p}=0.000$ ), other medical doctors in the family (RR: $1.431 ; 95 \%$ CI: $1.081-1.896 ; \mathrm{p}=0.014)$, prefer to work in the hospital (RR: 4.583 ; $95 \% \mathrm{CI}$ : 1.632 - 12.871; $\mathrm{p}=0.002$ ), prestige (RR: 1.312; 95\% CI: $1.052-1.637 ; \mathrm{p}=0.018$ ), and the social responsibility (RR: $1.297 ; 95 \% \mathrm{CI}: 1.026-1.638 ; \mathrm{p}=0.030$ ).

In Scotland, using a mixed-method design including a questionnaire survey and qualitative interviews among 42 new registered core and Acute Care Common Stem anesthesia trainees, Moore et al. [11] observed that the most critical determinants were the quality of training, personal health, senior support, staffing level, sustainability of working conditions, the morale of the team, future job prospects, and the equity of payment. In the USA, among 55 residents in the anesthesiology residency at Mayo Clinic in Rochester in 2011, Augustin et al. [12] found that the most important reasons for choosing anesthesiology were a "hands-on" specialty in 49\%, acute critical care in 33\%, opportunity to perform invasive procedures in $31 \%$, immediate gratification in work in $31 \%$, and the involvement of physiology and pharmacology in practice in $21 \%$.

This study had some limitations. First, it was monocentric. A national survey could be interesting to compare with other countries. Secondly, we used the questionnaire as a method for this study. A mixed-method design with qualitative reviews can clarify further item details. Thirdly, our subjects were resident doctors. A survey including medical students of the first cycle is interesting given that some traits could be changed over the years.

\section{Conclusion}

We recommend the succeeding: 1) Support students in their choice; 2) Correct misconceptions about certain specialties; 3) Promote clinical clerkship; 4) Encourage mentorship; 5) Increase the salary of at-risk specialties.

\section{Conflicts of Interest}

The authors declare no conflicts of interest regarding the publication of this paper.

\section{References}

[1] Moroccan Ministery of Health Human Resources Department (2019) Offre de soins. http://cartesanitaire.sante.gov.ma/dashboard/pages2/rh_med_19.html

[2] Guilloux, A.G.A., Ramos, J.A., Citron, I., Roa, L., Amundson, J., Massenburg B.B., Saluja, S., Miotto, B.A., Alonso, N. and Scheffer, M.C. (2019) Profiling Recent Med- 
ical Graduates Planning to Pursue Surgery, Anesthesia and Obstetrics in Brazil. BMC Medical Education, 19, Article No. 136.

https://doi.org/10.1186/s12909-019-1562-6

[3] Murdoch, M., Kressin, N., Fortier, L., Giuffre, P.A. and Oswald, L. (2001) Evaluating the Psychometric Properties of a Scale to Measure Medical Students' CareerRelated Values. Academic Medicine, 76, 157-165.

https://doi.org/10.1097/00001888-200102000-00015

[4] Gelb, A.W., Morriss, W., Johnson, W., Merry, A.F., Gelb, A.W., Merry, A.F. and International Standards for a Safe Practice of Anesthesia Workgroup. (2018) World Health Organization-World Federation of Societies of Anaesthesiologists (WHOWFSA) International Standards for a Safe Practice of Anesthesia. Canadian Journal of Anesthesia, 65, 698-708. https://doi.org/10.1007/s12630-018-1111-5

[5] Merry, A.F., Cooper, J.B., Soyannwo, O., Wilson, I.H., and Eichhorn, J.H. (2010) International Standards for a Safe Practice of Anesthesia 2010. Canadian Journal of Anesthesia, 57, 1027-1034. https://doi.org/10.1007/s12630-010-9381-6

[6] Oku, O.O., Oku, A.O., Edentekhe, T., Kalu, Q. and Edem, B.E. (2014) Specialty Choices among Graduating Medical Students in University of Calabar, Nigeria: Implications for Anesthesia Practice. Ain-Shams Journal of Anesthesiology, 7, 485-490. https://doi.org/10.4103/1687-7934.145673

[7] Abdul-Rahman, M., Aryee, G., Essuman, R., Djagbletey, R., Lamptey, E., Owoo, C. and Boni, F. (2015) Factors Influencing the Choice of Anaesthesia as a Field of Specialty in University of Ghana School of Medicine and Dentistry, Korle-Bu Teaching Hospital. Southern African Journal of Anaesthesia and Analgesia, 21, 166-168. https://doi.org/10.1080/22201181.2015.1089666

[8] Asad, N., Maqsood, A.H., Akhtar, N., Durrani, H., Taqi, A., Imtiaz, S. and Khaliq S. (2019) Anaesthesia as a Career: Identifying Factors that Influence Its Choice. Pakistan Journal of Medical \& Health Sciences, 13, 656-658.

[9] Alkhilaiwi, R.M., Alatassi, A., Almohawis, A.H., Alhumaid, T.A., Almazyad, K.A. and Bustami, R.T. (2018) Medical Students' Attitude toward Anesthesia as a Future Career. Saudi Journal of Anaesthesia, 12, 215-219. https://doi.org/10.4103/sja.SJA_367_17

[10] Tyagi, A., Kumar, S., Sethi, A.K. and Dhaliwal, U. (2012) Factors Influencing Career Choice in Anaesthesiology. Indian J Anaesth, 56, 342-347.

[11] Moore, J.N., McDiarmid, A.J., Johnston, P.W. and Cleland, J.A. (2017) Identifying and Exploring Factors Influencing Career Choice, Recruitment and Retention of Anaesthesia Trainees in the U.K. Postgraduate Medical Journal, 93, 61-66. https://doi.org/10.1136/postgradmedj-2015-133518

[12] Augustin, I.D., Long, T.R., Rose, S.H. and Wass, C.T. (2014) Recruitment of House Staff into Anesthesiology: A Longitudinal Evaluation of Factors Responsible for Selecting a Career in Anesthesiology and an Individual Training Program. Journal of Clinical Anesthesia, 26, 91-105. https://doi.org/10.1016/j.jclinane.2013.01.020 


\section{Appendix: Questionnaire}

A) Socio-demographic characteristics:

1) Age: ...years Gender: $M \square F \square$

2) Geographic origin: urban $\square$ rural

3) Faculty of medicine: Faculty of Marrakech $\square$ Other faculties $\square$

4) Marital status: Married $\square$ Single $\square$

5) Father's education level: illiterate $\square$ Primary $\square$ Secondary $\square$ High school University

6) Mother's education level: illiterate $\square$ Primary $\square$ Secondary $\square$ High school $\square$ University $\square$

7) Do your mother or father is a healthcare worker? No $\square$ Yes $\square$, if yes: Physician $\square$ Other $\square$

8) Year of the residency training: $1^{\text {st }} \square 2^{\text {nd }} \square 3^{\text {rd }} \square 4^{\text {th }} \square 5^{\text {th }}$

9) Specialty: ...

B) Criteria influencing the choice: Please rate each of the following items on a scale from 1 to 5 (1-Strongly disagree, 2-Disagree, 3-Neither disagree nor agree, 4-Agree, 5-Strongly agree) regarding their influence on your choice.

$\begin{array}{lllll}1 & 2 & 3 & 4 & 5\end{array}$

Hospital training completed during the externship

Content and quality of teaching of lectures

Attended workshops, round tables and conferences

Training during the intership

Duration of the residency training

Prestige and status of the specialty

Intellectual challenge

Desire practice in academic setting

Enjoy tending to patients' social and psychological needs

Interest in procedures and surgical techniques

Occupational risks (radiation, infectious diseases

Medico-legal risks

The pedagogical approach of the teachers of the department

Ward atmosphere

(organization, medical and paramedical staff, etc.)

Shift pace and workload

Flexible working hours

Availability of employment in the liberal sector

Assignment at the end of the specialty training

Financial aspects 


\section{Continued}

Your spouse's career and location

Personal profile (stress, etc.)

Socio-economic level (requirement of significant investment)

Influence of someone (parents, relatives, friends)

Life experience/Emotional shock

\section{Health reason}

Lifestyle 